\title{
A case of megalencephalic leukoencephalopathy with subcortical cysts (Van der Knaap disease)
}

\author{
P H Ariyawansa ${ }^{1}$, B H M N Katugaha ${ }^{2}$, T G P T Gamage ${ }^{3}$, H R T Dammika ${ }^{3}$, M G D G Wijewardena ${ }^{3}$
}

Sri Lanka Journal of Child Health, 2011; 40: 31-32

(Key words: Megalencephalic leukoencephalopathy with subcortical cysts; MLC; Van der Knaap Disease)

\section{Introduction}

Megalencephalic leukoencephalopathy with subcortical cysts (MLC) is a rare neurodegenerative disorder first described by Van der Knaap in $1995^{1}$. It is characterized by early onset macrocephaly which is an invariable feature. Slow degeneration of motor functions and mild mental deterioration are late findings ${ }^{1}$. Some patients have lived up to their 2 nd or 3 rd decades ${ }^{1}$. To the best of our knowledge this is the first reported case in Sri Lanka.

\section{Case report}

A 3 year old girl, born to non consanguineous parents, with an uneventful birth history following a normal pregnancy, presented with progressive enlargement of the head size from early months of life. According to the Child Health Development Record (CHDR) the head circumference (HC) was normal at birth, exceeded the 2SD limit for age at 6 months and after 9 months of age followed above and parallel to the 98th percentile (Figure1).

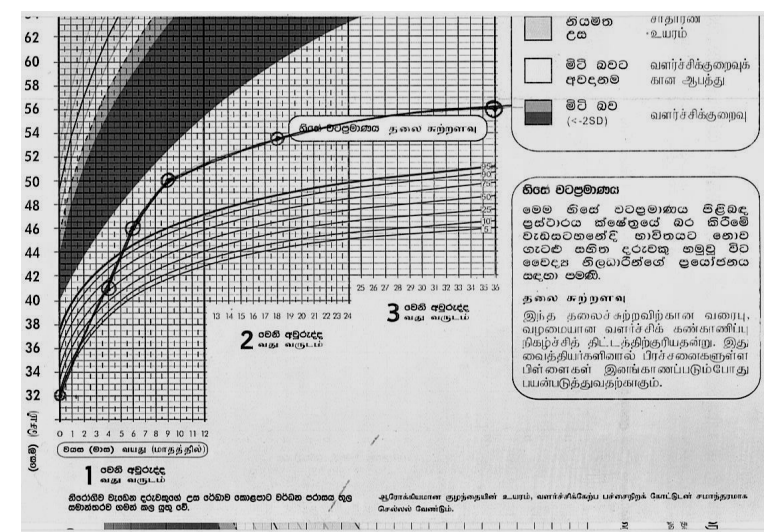

Figure 1 CHDR showing increase in $H C$

${ }^{1}$ Consultant Radiologist, ${ }^{2}$ Consultant Paediatrician, ${ }^{3}$ Paediatric Senior House officer, Sirimavo Bandaranaike Specialized Children's Hospital Peradeniya, Sri Lanka

(Received on 5 January 2010. Accepted on 19 February 2010)
The child had achieved age appropriate milestones up to the age of 9 months. She had developed unsteady gait and urinary incontinence at the age of 2 years. At the age of 3 years, she developed seizures which were easily controlled with sodium valproate.

On examination, there was macrocephaly ( $\mathrm{HC} 56 \mathrm{~cm}$, $>98^{\text {th }}$ percentile), unsteady gait, slurring of speech, extra-pyramidal signs and cerebellar ataxia. Magnetic resonance imaging (MRI) of the brain showed bilaterally symmetrical "swollen white matter" which was hypo-intense on T1 weighted sequences (Figure 1) and hyper-intense in T2 weighted sequences and FLAIR sequences suggestive of diffuse white matter degeneration. Characteristic subcortical cysts were seen in both temporal regions, both parietal regions and right frontal region. Deep structures and cerebellum were spared. Cerebral cortex was uninvolved. There was no enhancement following contrast administration.

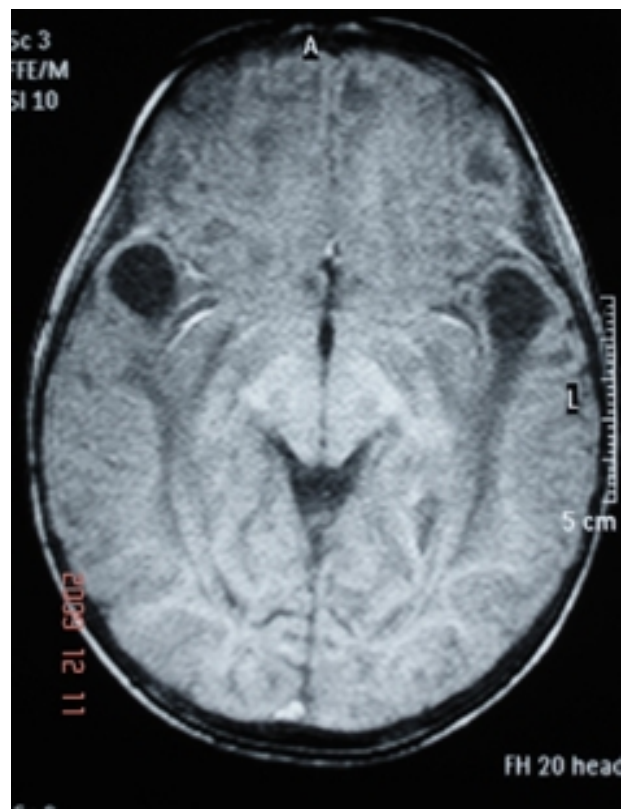

Figure 2 T1 weighted MRI of brain showing bilaterally symmetrical hypo-intense and swollen white matter \&subcortical cysts with sparing of cortex 


\section{Discussion}

MLC is an autosomal recessive disorder due to mutations in MLC1 gene ${ }^{2}$. The disease is more commonly found in some ethnicities like the Agrawal community in India, Libyan Jews and Turks where consanguinity is common ${ }^{3,4}$. In our case consanguinity was not present.

Macrocephaly may be present at birth but more frequently develops during the first year of life ${ }^{1}$. The degree of macrocephaly is variable and can be as much as 4 to 6 standard deviations (SDs) above the mean $^{5}$. The HC in this child was normal at birth and there was rapid growth since early months of life.

Almost all patients have early onset epilepsy ${ }^{1}$. This child too had seizures which were easily controlled. Other clinical symptoms that may be present are cerebellar ataxia, dysarthria and extrapyramidal symptoms like dystonia and athetosis ${ }^{1}$. Unsteady gait, slurring of speech, extra-pyramidal signs and cerebellar ataxia were present in our patient.

MLC can be diagnosed confidently by MRI which shows diffuse white matter changes and subcortical cysts ${ }^{1}$. Subcortical cysts are almost invariably present in the anterior temporal region and often in the frontoparietal region ${ }^{1}$. Over time the white matter swelling decreases and cerebral atrophy ensues ${ }^{1}$. Gray matter and deep white matter structures like corpus callosum, internal capsule and brain stem are relatively spared..Typical MRI features were seen in our patient.

The differential diagnosis of macrocephaly and leukoencephalopathy includes Canavan disease, Alexander disease, infantile-onset GM2 and GM1 gangliosidosis. In contrast to MLC these diseases have a rapidly progressive course of deterioration. In Canavan disease ${ }^{6}$, MRI shows involvement of cerebral white matter, thalamus and globus pallidus, which are spared in MLC. There is marked increase in the $\mathrm{N}$-acetylaspartate. Alexander disease ${ }^{7}$ leads to a megalencephaly and leukoencephalopathy with frontal predominance of MRI abnormalities and contrast enhancement of particular brain structures, which is not a feature of MLC. Cystic degeneration may occur in Alexander's disease, but deep frontal white matter is mainly affected ${ }^{7}$. MLC characteristically has an early onset and slow progression, whereas Canavan and Alexander disease have rapid progression. MRI in infantile GM2 gangliosidosis is characterized by prominent involvement of the basal ganglia and thalami in addition to the white matter abnormalities ${ }^{8}$. MRI features in infantile GM1 gangliosidosis are very similar to those of GM2 gangliosidosis. Demonstration of deficiency of beta galactosidase activity in leukocytes confirms the diagnosis.

\section{References}

1. Van der Knaap MS, Barth PG, Stroink H, van Nieuwenhuizen O, Arts WF, Hoogenraad F, et al. Leukoencephalopathy with swelling and a discrepantly mild clinical course in eight children. Ann Neurol 1995; 37: 324-34.

2. Leegwater FA, Boor PK, Yuan BQ, van der Steen J, Visser A, Konst AA, et al. Identification of novel mutations in MLC1 responsible for megalencephalic leukoencephalopathy with subcortical cysts. Hum Genet 2002; 110: 279-83.

3. Ben-Zeev B, Gross V, Kushnir T, Shalev R, Hoffman C, Shinar Y, et al. Vacuolating megalencephalic leukoencephalopathy in 12 Israeli patients. J Child Neurol 2001; 16: 93-9.

4. Singhal BS, Gursahani RD, Udani VP, Biniwale AA. Megalencephalic leukodystrophy in an Asian Indian ethnic group. Pediatr Neurol 1996; 14: 291-6.

5. Hari Krishnan K, Leema Pauline C, Kumaresan G, Vasantha Mallika TK, Megalencephalic leukoencephalopathy with subcortical cysts, Indian Pediatrics 2005; 42 (1): 60-3.

6. Marks HG, Caro PA, Wang ZY, Detre JA, Bogdan AR, Gusnard DA, et al. Use of computed tomography, magnetic resonance imaging, and localized $1 \mathrm{H}$ magnetic resonance spectroscopy in Canavan's disease: a case report. Ann Neurol 1991; 30: 106-10.

7. van der Knaap MS, Naidu S, Breiter SN, Blaser $\mathrm{S}$, Stroink H, Springer S, et al. Alexander disease: diagnosis with MR imaging. $\mathrm{Am} J$ Neuroradiol 2001; 22: 541-52.

8. Chen CY, Zimmerman RA, Lee CC, Chen FH, Yuh YS, Hsiao HS. Neuroimaging findings in late infantile GM1 gangliosidosis. $\mathrm{Am} J$ Neuroradiol 1998; 19: 1628-30. 